\title{
Ranking different factors influencing on development of tourism industry
}

\author{
Mojtaba Khalesi Ardakani*
}

Department of Management, Tehran Central Branch, Islamic Azad University, Tehran, Iran

\section{H R O N I C L E}

\section{Article history:}

Received July 28, 2013

Accepted 14 January 2014

Available online

February 272014

Keywords:

Tourism industry

TOPSIS

SAW

Taxonomy

\section{A B S T R A C T}

\begin{abstract}
Tourism industry plays an essential role on development of economy and it is considered as one of green industries. Many countries try to promote investment on tourism to create various job opportunities. This paper presents an empirical investigation to rank different factors influencing on tourism industry in city of Yazd, Iran. The proposed study uses three multiple criteria decision making techniques namely, Technique for Order of Preference by Similarity to Ideal Solution (TOPSIS), Simple Additive Weighting (SAW) and Taxonomy to rank 40 factors. The results indicate that factors such as Being located in the center axis of communication, Strengths in transportation, The ease of access to tourism destinations and Sufficient knowledge of some historical attractions are among important factors influencing tourism industry.
\end{abstract}

\section{Introduction}

Tourism industry plays an essential role on development of economy and it is considered as one of green industries. Many countries try to promote investment on tourism to create various job opportunities and there are many studies to detect important barriers. Some studies in tourism and transport have investigated the connection service between metro systems with urban airports to help in improve performance for long-term development (Michalena et al., 2009; Sánchez-Lozano et al., 2013). Liu et al. (2012, 2013), for instance, studied this issue using different multiple criteria decision-making (MCDM) techniques including DEMATEL decision-making trial and evaluation laboratory (DEMATEL), the DEMATEL-based analytic network process (DANP) and VIšekriterijumsko KOmpromisno Rangiranje (VIKOR), to rank the influential relationships among dimensions and criteria of the empirical case. Chiu et al. (2013) tried to develop some strategies to reduce the gaps in customer satisfaction caused by interdependence and feedback problems among dimensions and criteria to reach the aspiration level. They used a hybrid of DEMATEL, DEMATELbased Analytic Network Process (DANP), and VIKOR techniques to rank different factors. They also 
compared three real cases to illustrate how the proposed new hybrid MCDM model could improve estore business for development of tourism industry.

Hwang and Yoon (1981) first proposed technique for Order Preference by Similarity to Ideal Solution (TOPSIS). The method determines solutions from a finite set of alternatives and it is based on the concept that the chosen alternative should have the shortest distance from the positive ideal solution (PIS) and the farthest distance from the negative ideal solution (NIS).

Peng, K. H. (2012) proposed a new TOPSIS method called "Fuzzy Rasch" for generating fuzzy numbers to evaluate the competitiveness of the tourism industries in Asian countries. Alptekin and Büyüközkan (2011) presented an integrated case-based reasoning and MCDM system for Web based tourism destination planning. The method integrated case-based reasoning (CBR) system with Analytic Hierarchy Process (AHP) to enhance the accuracy and speed in case matching in tourism destination planning. Zhang et al. (2011) evaluated the tourism destination competitiveness (TDC) of the Yangtze River Delta in China with a two-step procedure. The first procedure included three hierarchies, 4 characteristics and 35 evaluation indices weighted by the information entropy weight (IEW). They applied TOPSIS method for the ranking analysis, which gave the most important index for each aspect by IEW.

Simple Additive Weighting (SAW) known as weighted linear combination or scoring techniques is a simple and most often used MCDM. According to Afshari et al. (2010) "The method is based on the weighted average and an evaluation score is measured for each alternative by multiplying the scaled value given to the alternative of that attribute with the weights of relative importance directly assigned by decision maker followed by summing of the products for all criteria". This method has been applied in various applications such as tourism industry (Giupponi, 2007).

Taxonomy is another popular MCDM techniques used for ranking existing alternatives based on development level by using matrix of alternatives and attributes relationship. Rostampour (2012) determined comparative ranking of agricultural development in different provinces of Iran using taxonomy technique. Taxonomy has been extensively used for ranking alternatives including tourism industry (Go, 1992).

\section{The proposed method}

In this section, we present the implementation of three MCDM techniques mentioned earlier in this section; namely, TOPSIS, SAW and Taxonomy for ranking 40 different factors influencing development of tourism industry in city of Yazd, Iran. Yazd is considered as the driest major city in Iran, with an average annual rainfall of only 60 millimeters, and it is the hottest north of the Persian Gulf coast, with summer temperatures very frequently above $40{ }^{\circ} \mathrm{C}$ in blazing sunshine with virtually no humidity. Even at night, the temperatures in summer are uncomfortable. During the winter, the days remain mild and sunny, but in the morning, the thin air and low cloudiness cause very cold temperatures, which falls well below $0{ }^{\circ} \mathrm{C}$. The city maintains a 3,000 years history, dating back to the time of the Median Empire known as Ysatis.

The current city name has been derived from Yazdegerd I, a Sassanid ruler and it was a Zoroastrian center during Sassanid times. After the Arab Islamic conquest of Persia, many Zoroastrians escaped to Yazd from neighboring provinces. Yazd is of the most importance center of Persian architecture. Because of its climate, it has one of the largest networks of aqueduct in the world, and Yazdi aqueduct makers are considered the most skilled in Iran. To handle the extremely hot summers, most old buildings in Yazd have magnificent wind catchers, and large underground areas (See Fig. 1). Table 1 shows details of the implementation of factors and ranking of these methods based on three MCDM techniques. 

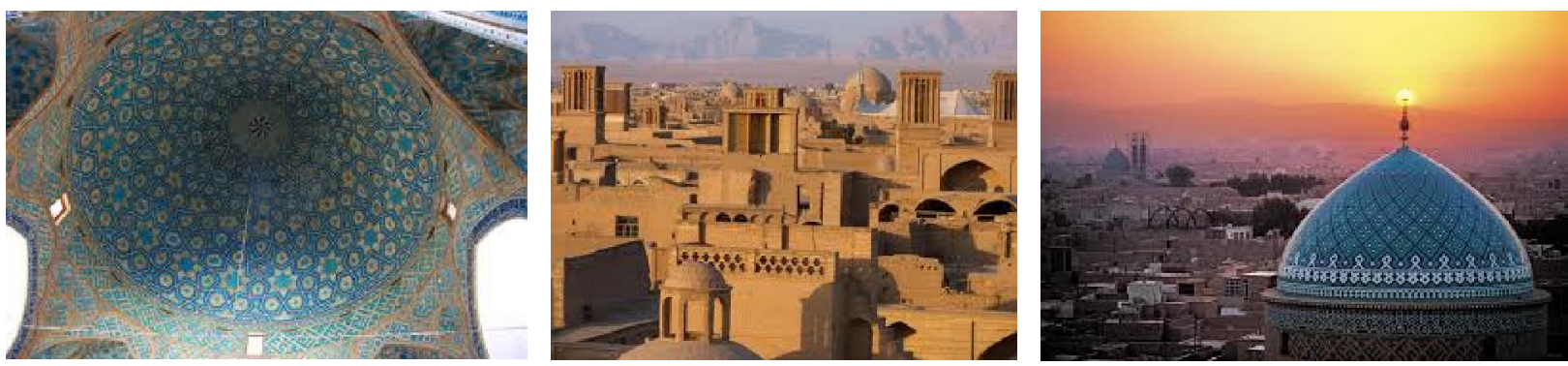

Fig. 1. The city of Yazd

Table 1

The summary of ranking factors based on TOPSIS, SAW and Taxonomy

\begin{tabular}{|c|c|c|c|c|c|c|}
\hline Item & Title & SAW & TOPSIS & Taxonomy & Mean & Rank \\
\hline 1 & Being located in the center axis of communication & 1 & 1 & 4 & 2 & 1 \\
\hline 2 & Strong transport fleet & 3 & 8 & 1 & 4 & 2 \\
\hline 3 & The ease of access to tourism destinations & 2 & 3.5 & 10.5 & 5.33 & 3 \\
\hline 4 & Sufficient knowledge of some historical attractions & 2 & 3.5 & 10.5 & 5.33 & 3 \\
\hline 5 & Increase safety in the border provinces in the country & 2 & 3.5 & 10.5 & 5.33 & 3 \\
\hline 6 & Good infrastructure for desert trekking fielder & 2 & 3.5 & 10.5 & 5.33 & 3 \\
\hline 7 & Global Communication & 4 & 6 & 7 & 5.66 & 4 \\
\hline 8 & Suitability of accommodation and welfare facilities & 5 & 7 & 6 & 6 & 5 \\
\hline 9 & Positive advertising media & 6 & 13 & 5 & 8 & 6 \\
\hline 10 & Airport facility services & 6 & 13 & 5 & 8 & 6 \\
\hline 11 & Religious and historical sites and architectural fabric of the & 6 & 13 & 5 & 8 & 6 \\
\hline 12 & The suitability of infrastructure, tourism development & 6 & 13 & 5 & 8 & 6 \\
\hline 13 & Social laws and regulations of the tourism industry & 6 & 13 & 5 & 8 & 6 \\
\hline 14 & Domestic customs & 7 & 10 & 8 & 8.33 & 7 \\
\hline 15 & Availability of signs, tips to guide tourists to tourist areas & 25 & 9 & 3 & 12.33 & 8 \\
\hline 16 & No specific credit allocation for the development of tourism & 8 & 18 & 11 & 12.33 & 8 \\
\hline 17 & Parking and tourist places & 10 & 19 & 10 & 13 & 9 \\
\hline 18 & Willingness of the private sector to invest in tourism sector & 7 & 23 & 12 & 14 & 10 \\
\hline 19 & Transmitters good tourist destination by Native & 11 & 21 & 15 & 15.66 & 11 \\
\hline 20 & Ease of access to shopping centers & 11 & 21 & 15 & 15.66 & 11 \\
\hline 21 & Political calm & 11 & 21 & 15 & 15.66 & 11 \\
\hline 22 & Training and use of expertise and experience in the tourism & 9 & 16.5 & 26.5 & 17.33 & 12 \\
\hline 23 & Attractive and the diversification of tourism & 9 & 16.5 & 26.5 & 17.33 & 12 \\
\hline 24 & Ease of regulation in getting Visa & 12 & 24.5 & 17.5 & 18 & 13 \\
\hline 25 & Less bureaucracy in administration & 12 & 24.5 & 17.5 & 18 & 13 \\
\hline 26 & Existence of rare species of plants and animals in protected & 13 & 27 & 15 & 18.33 & 14 \\
\hline 27 & Non-military threats & 14 & 28 & 19 & 20.33 & 15 \\
\hline 28 & Previous experience in driving tourists & 16 & 29 & 17 & 20.66 & 16 \\
\hline 29 & Lack of planning and public investment in tourism sector & 15 & 30 & 20 & 21.66 & 17 \\
\hline 30 & Availability of automated banking services & 17 & 31 & 21 & 23 & 18 \\
\hline 31 & Lack of inconsistent government policies & 26 & 26 & 18 & 23.33 & 19 \\
\hline 32 & Past tourists' experiences & 18 & 32 & 22 & 24 & 20 \\
\hline 33 & Knowledge of hosting tourists among citizens & 19 & 34 & 24 & 25.66 & 21 \\
\hline 34 & Communication systems such as power, phone or fax & 20 & 33 & 25 & 26 & 22 \\
\hline 35 & The lack of specific forces beside the tourist attraction of & 21 & 37 & 26 & 28 & 23 \\
\hline 36 & Adequate sanitary facilities & 27 & 35 & 23 & 28.33 & 24 \\
\hline 37 & Companies and amateur tourist guides & 22 & 38 & 28 & 29.33 & 25 \\
\hline 38 & No conflict between tourists' culture and city residence & 23 & 39 & 29 & 30.33 & 26 \\
\hline 39 & Peaceful coexistence of different religious faiths & 28 & 36 & 27 & 30.33 & 27 \\
\hline 40 & Secure post services & 24 & 40 & 30 & 31.33 & 28 \\
\hline
\end{tabular}

As we can observe from the results of Table 1, "Being located in the center axis of communication" is number one priority followed by "Strong transport fleet". The second group factors consists of four items, includes "The ease of access to tourism destinations", "Sufficient knowledge of some historical attractions", "Increase safety in the border provinces in the country" and "Good infrastructure for desert trekking fielder". 


\section{Discussion and conclusion}

In this paper, we have presented an empirical investigation to determine important factors influencing development of tourism industry in city of Yazd, Iran. The proposed study has determined 40 different factors and, using three methods of TOPSIS, SAW and Taxonomy, the factors have been ranked, accordingly. Tourism industry has been one of the most popular industries for development of economy and it can help various societies become familiar with other nations' culture and history. The survey can be extended using other MCDM techniques such as fuzzy TOPSIS, fuzzy DEMATEL, etc. and we leave it for interested researchers for further investigations.

\section{Acknowledgement}

The authors would like to thank the anonymous referees for constructive comments on earlier version of this work.

\section{References}

Afshari, A., Mojahed, M., \& Mohd Yusuff, R. (2010). Simple additive weighting approach to personnel selection problem. International Journal of Innovation, Management and Technology, 1(5), 511-515.

Alptekin, G. I., \& Büyüközkan, G. (2011). An integrated case-based reasoning and MCDM system for Web based tourism destination planning. Expert Systems with Applications, 38(3), 2125-2132.

Chiu, W. Y., Tzeng, G. H., \& Li, H. L. (2013). A new hybrid MCDM model combining DANP with VIKOR to improve e-store business. Knowledge-Based Systems, 37, 48-61.

Giupponi, C. (2007). Decision support systems for implementing the European water framework directive: the MULINO approach. Environmental Modelling \& Software, 22(2), 248-258.

Go, F. M., Milne, D., \& Whittles, L. J. (1992). Communities as destinations: a marketing taxonomy for the effective implementation of the tourism action plan. Journal of Travel Research, 30(4), 3137.

Huang, J. H., \& Peng, K. H. (2012). Fuzzy Rasch model in TOPSIS: A new approach for generating fuzzy numbers to assess the competitiveness of the tourism industries in Asian countries. Tourism Management, 33(2), 456-465.

Hwang, C.L., \& Yoon, K. (1981). Multiple Attribute Decision Making: Methods and Applications. New York: Springer-Verlag.

Liu, C. H., Tzeng, G. H., \& Lee, M. H. (2012). Improving tourism policy implementation-the use of hybrid MCDM models. Tourism Management, 33(2), 413-426.

Liu, C. H., Tzeng, G. H., Lee, M. H., \& Lee, P. Y. (2013). Improving metro-airport connection service for tourism development: Using hybrid MCDM models. Tourism Management Perspectives, 6, 95-107.

Michalena, E., Hills, J., \& Amat, J. P. (2009). Developing sustainable tourism, using a multicriteria analysis on renewable energy in Mediterranean Islands.Energy for Sustainable Development, 13(2), 129-136.

Rostampour, S. (2012). Ranking provinces based on development scale in agriculture sector using taxonomy technique. Management Science Letters, 2(5), 1813-1818.

Sánchez-Lozano, J. M., Teruel-Solano, J., Soto-Elvira, P. L., \& Socorro García-Cascales, M. (2013). Geographical Information Systems (GIS) and Multi-Criteria Decision Making (MCDM) methods for the evaluation of solar farms locations: Case study in south-eastern Spain. Renewable and Sustainable Energy Reviews, 24, 544-556.

Zhang, H., Gu, C. L., Gu, L. W., \& Zhang, Y. (2011). The evaluation of tourism destination competitiveness by TOPSIS \& information entropy-A case in the Yangtze River Delta of China. Tourism Management, 32(2), 443-451. 